\title{
Heat Transfer in Cadmium Telluride-Water Nanofluid over a Vertical Cone under the Effects of Magnetic Field inside Porous Medium
}

\author{
Hanifa Hanif $1,2\left(\mathbb{D}\right.$, Ilyas Khan ${ }^{3, * \mathbb{D}}$, Sharidan Shafie ${ }^{2}$ and Waqar A. Khan ${ }^{4}$ \\ 1 Department of Mathematics, Faculty of Basic Sciences, Sardar Bahadur Khan Women's University, \\ Quetta 87300, Pakistan; hanihahanif@outlook.com \\ 2 Department of Mathematical Sciences, Faculty of Science, Universiti Teknologi Malaysia, Johor Bahru 81310, \\ Johor, Malaysia; sharidan@utm.my \\ 3 Faculty of Mathematics and Statistics, Ton Duc Thang University, Ho Chi Minh City 72915, Vietnam \\ 4 Department of Mechanical Engineering, College of Engineering, Prince Mohammad Bin Fahad University, \\ Al Khobar 31952, Saudi Arabia; wkhan@pmu.edu.sa \\ * Correspondence: ilyaskhan@tdtu.edu.vn
}

Received: 14 September 2019; Accepted: 17 October 2019; Published: 18 December 2019

\begin{abstract}
The present research provides a numerical investigation of two dimensional nanofluid flow over an inverted cone inside a porous medium. The model is developed to incorporate non-spherical shapes of $\mathrm{CdTe}$-nanoparticles in water based fluid. Simultaneous effects of pertinent parameters like volume fraction, Reynold number, Hartmann number, porosity, Grashof number, radiation parameter and Peclet number on temperature distribution and velocity profile are studied and illustrated graphically. In addition, the corresponding computational results of Nusselt number and skin frication for regulating parameters are also presented in graphs and tables. The highest Nusselt number is observed for blade-shaped $\mathrm{CdTe}$ particles. Furthermore, the thermal conductivity and viscosity are also calculated for non-spherical shapes of $C d T e$ nanoparticles. The result showed that the thermal conductivity of nanofluid with blade-shaped particles is $0.94 \%$ and $1.93 \%$ greater than platelet and brick type particles. The computational results for the special case are validated by comparisons with the presented results in previous studies and the results are in perfect agreement.
\end{abstract}

Keywords: magnetohydrodynamics; nanofluid; vertical cone; finite difference method

\section{Introduction}

A stable crystalline/powder cadmium telluride ( $C d T e)$ is formed with cadmium (metallic) and telluride (crystalline). Margottet was the first who introduced $C d T e$ while reacting metals with telluride at red heat [1]. The bonding structure of CdTe is shown in Figure 1. CdTe plays important role in several industrial applications. It has magnificent properties like high optical absorption, the ability to absorb sunlight at ideal length, band gap (1.5 ev), abundant. CdTe thin films are commercially used in solar cells due to its magnificent properties. CdTe thin film $(2 \mu \mathrm{m})$ has capability capture $100 \%$ solar radiation [2]. Owing to that fact, $C d T e$-solar cells are the leading candidate in photovoltaic development. $C d T e$-solar cells have been discussed by many researchers. Furthermore, their thermal and electrical properties have also attracted the attention of researchers [3-7]. However, researchers did not pay attention to improving the thermal performance of weak convectional fluid using $C d T e$ nanoparticles. To the best of authors' knowledge, for the first time, the heat transfer intensification in ethylene glycol by suspension of $C d T e$ nanoparticles is worked out by Hanif et al. [8]. 

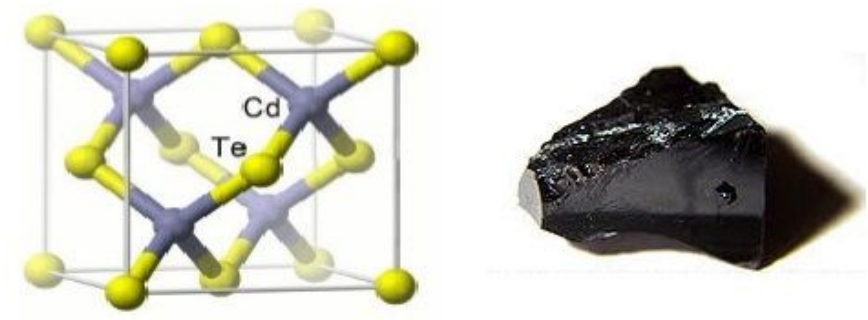

Figure 1. Bonding structure of $C d T e$.

In thermal systems, the properties of convectional heat transfer fluid are neither sufficient nor effective due to their low thermal conductivity. Therefore, researchers are more interested in nanofluid compared with regular convectional fluid since they are capable to improve the efficiency of thermal system due to increased thermal conductivity. A nanofluid is a colloidal mixture of regular fluid and nanoparticles. It has been shown that certain combinations of nano-sized particles and fluids possessed comparatively higher thermal rates than the regular fluid. The potential uses of nanofluid are typically in the heat transfer region, where a small concentration of nanoparticles often intensifies the heat transfer rates, for instance, see References [9-14].

Nanofluids have unique properties like viscosity and thermal conductivity and these properties vary by changing base fluid, size, shape, type and volume fraction of nanoparticles. Over the past few years, several studies have been done using different shapes and sizes of nanoparticles for the purpose of better thermal performance in thermal systems. Khan [15] discussed different shapes of $\mathrm{MoS}_{2}$-water based nanofluid in the presence of a magnetic field. It was concluded that blade-shaped particles gained $8.1 \%, 4.8 \%, 4 \%, 3.4 \%$ and $0.2 \%$ greater heat transfer rates than spherical, brick, cylinder and platelet shaped of $\mathrm{MoS}_{2}-\mathrm{H}_{2} \mathrm{O}$ nanofluid. Hassan et al. [16] compared the heat transfer rates of three different shapes (prolate, oblate and sphere) of $\mathrm{Fe}_{3} \mathrm{O}_{4}$ nanoparticles in water based nanofluid over a rotating disc. They found that maximum temperature rates are attained by prolate shaped nanoparticles. Moreover, the temperature rates are higher when a magnetic field is considered. Magnetohydrodynamics (MHD) force convection in water based nanofluid, considering different shapes of $\mathrm{CuO}$ particles, is studied numerically by sheikholeslami et al. [17]. The results showed that platelet shape particles gained maximum heat transfer rates. Also, the temperature gradient decreases the function of the Hartmann number. Sheikholeslami et al. [18] studied the shape variation in $\mathrm{Al}_{2} \mathrm{O}_{3}$ nanofluid in a permeable enclosure with MHD effects using the Darcy model. Hassan et al. [19] discussed the shape effects of iron nanoparticles in convectional ferrofluid flow over a rotating disk in the presence of an oscillating magnetic field. Hamid et al. [20] explored the shape effects of $\mathrm{MoS}_{2}$ nanoparticles on rotating fluid flow through a stretching elastic surface. Sheikholeslami et al. [21] investigated the escalation of heat transfer in ferrofluid inside a porous enclosure under the shape effects of $\mathrm{Fe}_{3} \mathrm{O}_{4}$ particles. Akbar et al. [22] studied the shape effects of nano-scale shape particles on the peristaltic flow of water based nanofluid in combination with magnetic field. Shi et al. [23] analyzed heat transfer combined with entropy generation in nanofluid flow through a channel using different shapes of $\mathrm{CuO}$-nanoparticles. Kumar et al. [24] investigated shape effects of $\mathrm{Cu}$ nanoparticles in water based nanofluid in a channel. They found an augmentation in Nusselt number due to the increment in thermal radiation and Rayleigh number, whereas a reverse trend was found by increasing the Hartmann number. Some interesting experimental and theoretical work on nanoparticle shape effects can be found in References [25-31].

In several real-life situations, fluid flow over a cone is in high demand, for example in healthcare systems, aeronautical engineering, energy storage, astrophysics, space technology, and so forth. Also, in chemical industry, canonical surfaces have been used in filtering, pumping, drilling and degassing machines, and so forth. It is therefore important not only to research these parameters, but also to have an idea of the behavior of liquid fluid flow when it flows along this shape in particular. It is 
also important to understand and forecast the flow nature and the involvement of nanoparticles in applications for heat transfer to be used in industrial chemical processes.

A literature survey reveals that the frequently used nanoparticles in nano thermal sciences are $\mathrm{Al}_{2} \mathrm{O}_{3}, \mathrm{Cu}$ and carbon nanotubes (CNTs) and so forth. Also, spherical nanoparticles are the most common particles considered by researchers but, when it comes to their application and significance, they are limited. Owing to the fact, this study incorporates the non-spherical $C d T e$ nanoparticles. More precisely, blade, brick and platelet shapes are taken into account. We believe a numerical study on different particle shapes of $C d T e$ contained in water based fluid has not yet been reported. Therefore, this is the first attempt to analyse heat transfer rates in water based nanofluid under the shape effects of $C d T e$ nanoparticles. Furthermore, radiation effects on natural convection flow over a vertical cone in the presence of a magnetic field are also discussed. The thermo-physical properties of base fluid water and CdTe nanoparticles are tabulated in Table 1. The effects of regulating parameters $\varphi, \mathrm{K}, \mathrm{Ha}, \mathrm{Gr}$ and $R d$ on temperature distribution, velocity profile are illustrated graphically and discussed in detail. Furthermore, the numerical results for Nusselt number $N u_{x}$ and skin friction $\tau_{x}$ under the influence of active parameters are also tabulated. For validation purposes, the computed results for some special cases are compared with the results of previously published work.

Table 1. Thermal and mechanical properties of water [15] and CdTe nanoparticles.

\begin{tabular}{cccc}
\hline Materials & Water & CdTe & Reference \\
\hline$\rho\left(\mathrm{kg} / \mathrm{m}^{3}\right)$ & 997.1 & 5855 & {$[32]$} \\
$C_{p}(\mathrm{~J} / \mathrm{kgK})$ & 4179 & 209 & {$[33]$} \\
$k(\mathrm{~W} / \mathrm{mK})$ & 0.613 & 7.5 & {$[34]$} \\
$\beta\left(\mathrm{K}^{-1}\right)$ & $21 \times 10^{-5}$ & $0.5 \times 10^{-5}$ & {$[34]$} \\
$\sigma=1 /$ resistivity $\left(\mathrm{Sm}^{-1}\right)$ & $0.55 \times 10^{-5}$ & $0.2 \times 10^{-7}$ & {$[35]$} \\
\hline
\end{tabular}

\section{Mathematical Formulation}

A free convection in water based $C d T e$ nanofluid over an inverted cone inside a porous medium is considered. In addition, three different shapes of $C d T e$ nanoparticles, namely, blade, brick and platelet are taken into account. The surface of the cone is taken as $x$-axis and normal to the cone is referred to $y$-axis. A uniform magnetic field of strength $B_{0}$ is considered normal to $x$-axis, see Figure 2 . The nanofluid is supposed to be electrically conducting due to an applied magnetic field. The induced magnetic field can be neglected since the Reynold number is sufficiently small. Initially $(\bar{t} \leq 0)$, the temperature distribution of the cone surface is considered the same as the surrounding fluid, that is, $T_{\infty}$. Thereafter $(\bar{t}>0)$, temperature $T$ of the nanofluid at the surface of cone increased to $T_{w}=T_{\infty}+c \bar{x}^{n}$. The 2D unsteady, unidirectional and incompressible nanofluid together with Boussinesq approximation can be written as

$$
\begin{aligned}
& \nabla \cdot(r \mathbf{v})=0, \\
& \rho_{n f}\left(\frac{\partial \bar{u}}{\partial \bar{t}}+(\mathbf{v} \cdot \nabla) \bar{u}\right)=\mu_{n f} \frac{\partial^{2} \bar{u}}{\partial \bar{y}^{2}}-\sigma_{n f} B_{0}^{2} \bar{u}-\frac{\mu_{n f}}{k_{0}} \bar{u}+g(\rho \beta)_{n f}\left(\bar{T}-T_{\infty}\right) \cos \phi, \\
& \left(\rho C_{p}\right)_{n f}\left(\frac{\partial \bar{T}}{\partial \bar{t}}+(\mathbf{v} \cdot \nabla) \bar{T}\right)=k_{n f} \frac{\partial^{2} \bar{T}}{\partial \bar{y}^{2}}-\frac{\partial q_{r}}{\partial \bar{y}} .
\end{aligned}
$$


where $\mathbf{v}=(\bar{u}(\bar{x}, \bar{y}, t), \bar{v}(\bar{x}, \bar{y}, t))$ and $\bar{T}=\bar{T}(\bar{x}, \bar{y}, t)$ represent 2-dimensional velocity in $(\bar{x}, \bar{y})-$ plane and temperature receptively. The mathematical expressions for nanofluid properties are tabulated in Table 2 . The appropriate initial boundary conditions are:

$$
\begin{array}{rll}
\bar{t} \leq 0: \bar{u}=0, & \bar{v}=0, & \bar{T}=T_{\infty}, \\
\bar{t}>0: \bar{u}=0, & \bar{v}=0, & \bar{T}=T_{\infty}+c \bar{x}^{n} \quad \text { at } \quad \bar{y}=0, \\
\bar{u}=0, & \bar{T}=T_{\infty} \quad \text { at } \quad \bar{x}=0, \\
\bar{u} \rightarrow 0, & \bar{T} \rightarrow T_{\infty} \quad \text { as } \quad \bar{y} \rightarrow \infty .
\end{array}
$$

\begin{tabular}{|c|c|c|}
\hline Properties & Nanofluid & References \\
\hline Density & $\rho_{n f}=(1-\varphi) \rho_{f}+\varphi \rho_{s}$ & [36] \\
\hline Viscosity & $\begin{array}{l}\mu_{n f}=\mu_{f}\left(1+a_{0} \varphi+b_{0} \varphi^{2}\right) \\
\text { where } a_{0} \text { and } b_{0} \text { are shape } \\
\text { constants given in Table } 3 .\end{array}$ & [15] \\
\hline Thermal expansion & $(\rho \beta)_{n f}=(1-\varphi)(\rho \beta)_{f}+\varphi(\rho \beta)_{s}$ & [37] \\
\hline Heat capacitance & $\left(\rho C_{p}\right)_{n f}=(1-\varphi)\left(\rho C_{p}\right)_{f}+\varphi\left(\rho C_{p}\right)_{s}$ & [37] \\
\hline Thermal conductivity & $\begin{aligned} \frac{k_{n f}}{k_{f}}= & \frac{\left(k_{s}+(m-1) k_{f}\right)+(m-1) \varphi\left(k_{s}-k_{f}\right)}{\left(k_{s}+(m-1) k_{f}\right)-\varphi\left(k_{s}-k_{f}\right)} \\
& \text { with } m=3 / \psi_{0}, \text { where } \psi_{0} \text { is the } \\
& \text { sphericity and given in Table } 3 .\end{aligned}$ & [24] \\
\hline Electrical conductivity & $\frac{\sigma_{n f}}{\sigma_{f}}=1+\frac{3 \varphi\left(\frac{\sigma_{s}}{\sigma_{f}}-1\right)}{\left(\frac{\sigma_{s}}{\sigma_{f}}+2\right)-\varphi\left(\frac{\sigma_{s}}{\sigma_{f}}-1\right)}$ & [37] \\
\hline
\end{tabular}

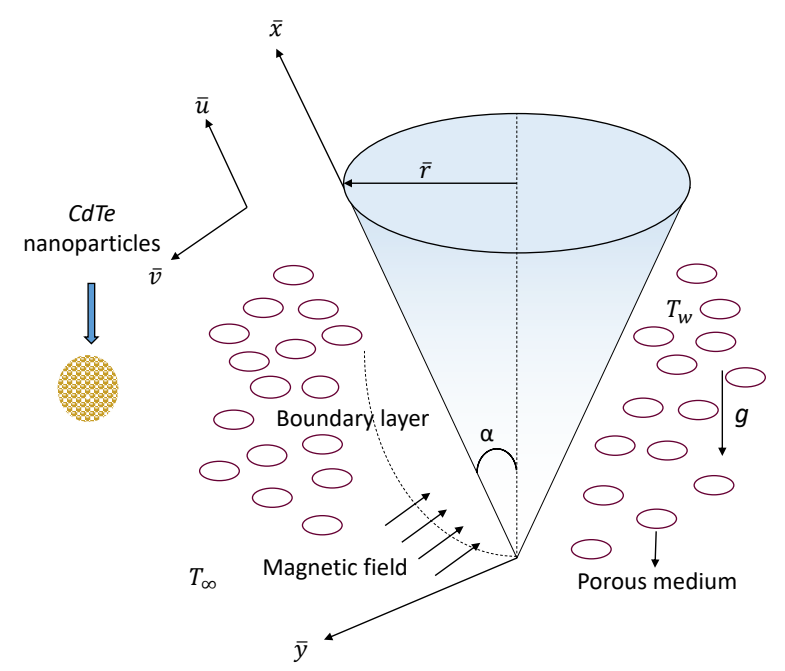

Figure 2. Problem schematics and geometrical coordinates.

Table 2. Mathematical expressions for nanofluid properties. 
Table 3. The shape constants $a_{0}, b_{0}$ and sphericity $\psi_{0}$ of nanoparticles [15].

\begin{tabular}{ccccc}
\hline \multirow{2}{*}{ Particle Category } & \multicolumn{3}{c}{ Shape Constants } & Sphericity \\
\cline { 2 - 4 } Blade & $a_{0}$ & $b_{0}$ & $\psi_{0}$ \\
\hline Brick & 14.6 & 123.3 & 0.36 \\
& 1.9 & 471.4 & 0.81 \\
Platelet & 37.1 & 612.6 & 0.52 \\
\hline
\end{tabular}

Rosseland approximation for radiative heat flux is (see Reference [38]):

$$
q_{r}=-\frac{4 \sigma_{b}}{3 k_{b}} \frac{\partial \bar{T}^{4}}{\partial \bar{y}}
$$

where $\sigma_{b}$ and $k_{b}$ denote Stefan-Boltzman and the absorption coefficient, respectively. Suppose the difference $\bar{T}-T_{\infty}$ inside flow is sufficiently small and $\bar{T}^{4}$ can be expanded by about $T_{\infty}$ by using the Taylor series. Hence, the approximation of $\bar{T}^{4}$ by neglecting higher orders:

$$
\bar{T}^{4} \approx T_{\infty}^{4}+4 T_{\infty}^{3}\left(\bar{T}-T_{\infty}\right) .
$$

Thereafter, using Equations (5) and (6) into Equation (3) leads to

$$
\left(\rho C_{p}\right)_{n f}\left(\frac{\partial \bar{T}}{\partial \bar{t}}+(\mathbf{v} \cdot \nabla) \bar{T}\right)=\left(k_{n f}+\frac{16 \sigma_{b}}{3 k_{b}} T_{\infty}^{3}\right) \frac{\partial^{2} \bar{T}}{\partial \bar{y}^{2}} .
$$

Invoking the following appropriate non-dimensional quantities

$$
\begin{aligned}
& x=\frac{\bar{x}}{\bar{L}}, \quad y=\frac{\bar{y}}{L^{\prime}}, r=\frac{\bar{r}}{L^{\prime}} \quad t=\frac{\bar{t} u_{0}}{L}, \\
& u=\frac{\bar{u}}{u_{0}}, \quad v=\frac{\bar{v}}{u_{0}}, \quad T=\frac{\left(\bar{T}-T_{\infty}\right)}{\left(T_{w}-T_{\infty}\right)}, \quad \tau_{x}=\frac{\tau_{\bar{x}} L}{\mu_{f} u_{0}},
\end{aligned}
$$

in Equations (1), (2) and (7) together with nanofluid properties defined in Table 2. We have,

$$
\begin{aligned}
\frac{\partial}{\partial x}(r u)+\frac{\partial}{\partial y}(r v) & =0, \\
\phi_{1} \operatorname{Re}\left[\frac{\partial u}{\partial t}+u \frac{\partial u}{\partial x}+v \frac{\partial u}{\partial y}\right] & =\phi_{2} \frac{\partial^{2} u}{\partial y^{2}}-\phi_{2} \frac{1}{K} u-\phi_{3} H a^{2} u+\phi_{4} G r T \cos \phi, \\
\phi_{5} \operatorname{Pe}\left[\frac{\partial T}{\partial t}+u \frac{\partial T}{\partial x}+v \frac{\partial T}{\partial y}\right] & =\left(\phi_{6}+R d\right) \frac{\partial^{2} T}{\partial y^{2}},
\end{aligned}
$$


where

$$
\begin{aligned}
& \phi_{1}=(1-\varphi)+\varphi \frac{\rho_{s}}{\rho_{f}}, \quad \phi_{2}=1+a_{0} \varphi+b_{0} \varphi^{2}, \quad \phi_{3}=\frac{\sigma_{n f}}{\sigma_{f}}, \\
& \phi_{4}=(1-\varphi)+\varphi \frac{(\rho \beta)_{s}}{(\rho \beta)_{f}}, \quad \phi_{5}=(1-\varphi)+\varphi \frac{\left(\rho C_{p}\right)_{s}}{\left(\rho C_{p}\right)_{f}}, \quad \phi_{6}=\frac{k_{n f}}{k_{f}}, \\
& \operatorname{Re}=\frac{u_{0} L}{v_{f}}, \quad \frac{1}{K}=\frac{L^{2}}{k_{0}}, \quad H a=B_{0} L \sqrt{\frac{\sigma_{f}}{\mu_{f}}}, \\
& G r=\frac{g \beta_{f}\left(T_{w}-T_{\infty}\right) L^{2}}{v_{f} u_{0}}, \quad P e=\frac{u_{0} L(\rho C p)_{f}}{k_{f}}, \quad \quad R d=\frac{16 \sigma_{b} T_{\infty}^{3}}{3 k_{b} k_{f}} .
\end{aligned}
$$

Here, $\phi_{1}-\phi_{6}$ refer to nanofluid constants. $R e, K, H a, G r, R d$, and Pe represent the Reynold's number, permeability parameter, Hartmann number, Grashof number, radiation parameter, and Peclet number respectively. The dimensionless form of Equation (4) is:

$$
\begin{array}{rlrl}
t \leq 0: u=0, & v=0, & T=0, \\
t>0: u=0, & v=0, & T=x^{n} \quad \text { at } y=0, \\
u=0, & T=0 \text { at } x=0, \\
u \rightarrow 0, & T \rightarrow 0 \text { as } y \rightarrow \infty .
\end{array}
$$

\section{Nusselt Number and Skin Friction}

Inducing non-dimensional parameters Equation (8) in Local Nusselt number $N u_{\bar{x}}$ and skin friction coefficient $\tau_{\bar{x}}$ defined below,

$$
N u_{\bar{x}}=\frac{1}{k_{f}\left(T_{w}-T_{\infty}\right)}\left[-k_{n f} \bar{x}\left(\frac{\partial \bar{T}}{\partial \bar{y}}\right)_{\bar{y}=0}+\left(q_{r}\right)_{\bar{y}=0}\right], \quad \tau_{\bar{x}}=\mu_{n f}\left(\frac{\partial \bar{u}}{\partial \bar{y}}\right)_{\bar{y}=0} .
$$

We have,

$$
N u_{x}=-x\left(\phi_{6}+R d\right)\left(\frac{\partial T}{\partial y}\right)_{y=0}, \quad \tau_{x}=\phi_{2}\left(\frac{\partial u}{\partial y}\right)_{y=0} .
$$

\section{Numerical Analysis}

The resulting system of non-linear coupled Equations (9)-(11) along with corresponding conditions Equation (13) is discretized by a finite difference scheme, namely, the Crank Nicolson method. It is an implicit, accurate, fast convergent, and an unconditionally stable method. This scheme approximates the equations at an average of current and forward time level, that is, $n^{\text {th }}$ and $(n+1)^{\text {th }}$ time level.

The rectangular area of integration has limits $x=1$ and $y=15$. Here $y$ corresponds to $y=\infty$ which positions quite away from exterior of the momentum and thermal boundary layers. The time step is taken as small as $\Delta t=0.01$ combined with the mesh size $\Delta x=0.05, \Delta y=0.05$ in $x$ and $y$ direction, respectively. For the convergent solution, the numerical iterations are repeated for several time. The solution is supposed to be converged when an absolute error approaches $1 e^{-5}$ for all grid nodes.

\section{Graphical Results and Discussion}

The different shapes of CdTe particles in the MHD flow of cadmium telluride nanofluid past a vertical cone with thermal radiation effects are considered. The Hamilton and Crosser model 
[39] is used for the thermal conductivity of different shapes of CdTe nanoparticles. For validation purposes, some limited cases of the current study are compared with the numerical results provided in References [40,41], as shown in Table 4 and the results are in excellent agreement.

Variational effects of of regulating parameters particle volume fraction $(\varphi=0,0.01,0.02,0.03)$, porosity parameter $(K=0.5,1.5,2.5,3.5)$, Hartmann number $(M=0,2,4,6)$, thermal Grashof number $(G r=0.1,0.3,0.5,0.7)$, and thermal radiation $(\mathrm{Rd}=0,1,2,3)$ on the temperature and velocity profiles are plotted graphically. Additionally, the influence of regulating parameters on physical quantities $N u_{x}$ and $\tau_{x}$ are also calculated and tabulated in Tables $5-7$. The results are reasonable and more close to physical expectations.

Figures 3-12 have plotted for different shapes of $C d T e$ nanoparticles under the influence of emerging parameters $(\varphi, K, H a, G r$ and $R d)$ at fixed parameters $\phi=\pi / 4, R e=1, P e=0.3$ and $n=0.5$. Figures 3 and 4 depict the change in temperature and velocity field for different shapes of $C d T e$ nanoparticles under the effect of particle volume fraction $\varphi$. It is perceived that with an augment in $\varphi$ the temperature distribution increases. Whereas the velocity field showed an opposite behaviour. The maximum increase in temperature and minimum decrease in velocity are observed for platelet-shaped nanoparticles followed by blade and brick-shaped nanoparticles.

Table 4. Comparison of steady state local Nusselt number and skin friction at $x=1$ for different values of $P e$ when $\varphi=1 / K=H a=R d=n=0$, and $R e=G r=1$.

\begin{tabular}{ccccccc}
\hline \multirow{2}{*}{$\boldsymbol{P} e$} & \multicolumn{3}{c}{$N \boldsymbol{u}_{\boldsymbol{x}}$} & & \multicolumn{3}{c}{$\tau_{x}$} \\
\cline { 2 - 7 } & {$[40]$} & {$[41]$} & Present & {$[40]$} & {$[41]$} & Present \\
\hline 0.01 & 0.0749 & 0.0751 & 0.0884 & 1.3551 & 1.3549 & 1.3158 \\
0.1 & 0.2116 & 0.2116 & 0.2109 & 1.0960 & 1.0962 & 1.0985 \\
1 & 0.5109 & 0.5111 & 0.5119 & 0.7699 & 0.7697 & 0.7696 \\
10 & 1.0339 & 1.0342 & 1.0337 & 0.4877 & 0.4877 & 0.4861 \\
100 & 1.9226 & 1.9230 & 1.9235 & 0.2896 & 0.2895 & 0.2882 \\
\hline
\end{tabular}

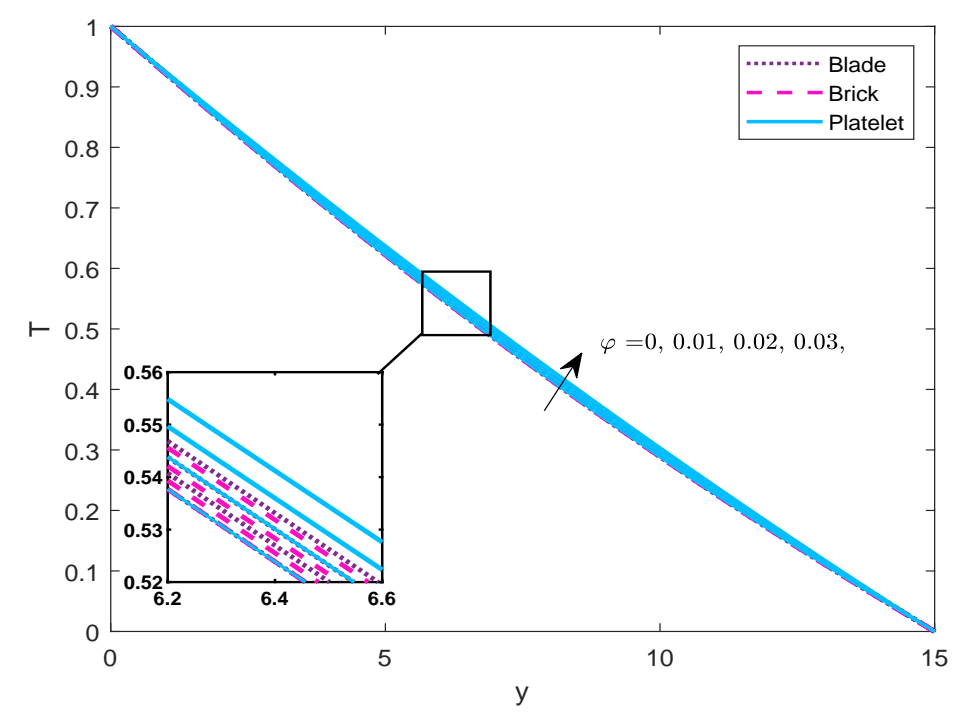

Figure 3. Influence of $\varphi$ on temperature distribution when $K=0.5, H a=2, G r=0.3$, and $R d=3$. 


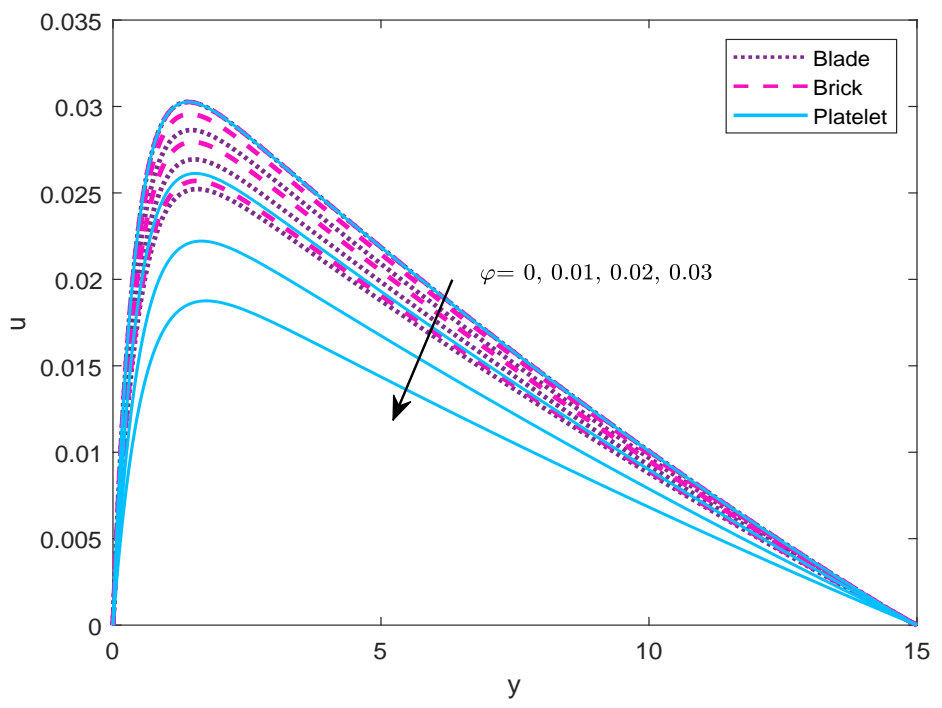

Figure 4. Influence of $\varphi$ on velocity profile when $K=0.5, H a=2, G r=0.3$, and $R d=3$.

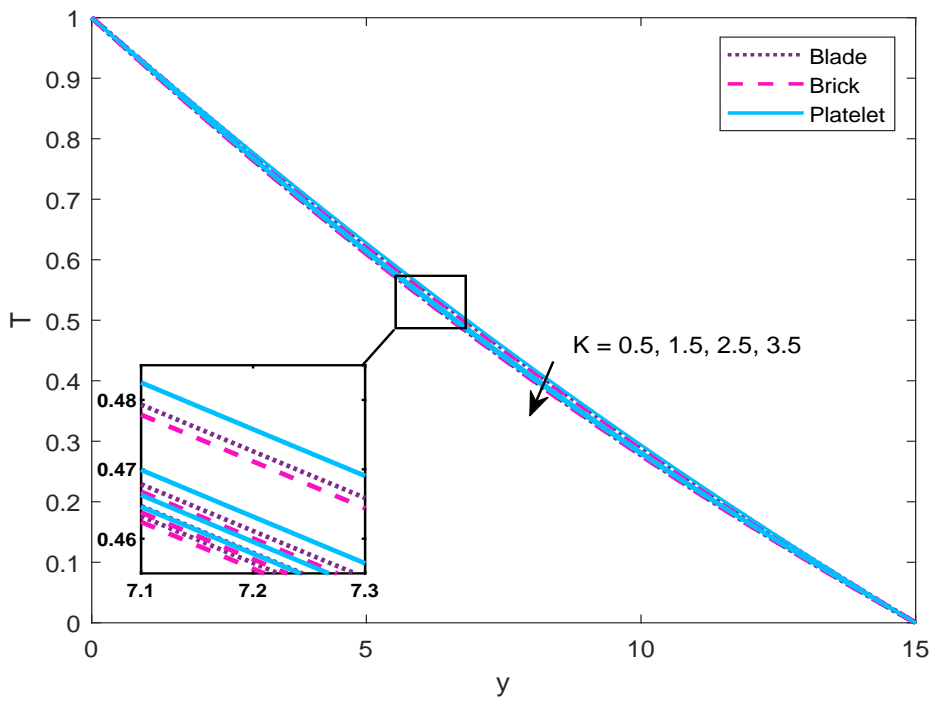

Figure 5. Influence of $K$ on temperature distribution when $\varphi=0.01, \mathrm{Ha}=2, \mathrm{Gr}=0.3$, and $\mathrm{Rd}=3$.

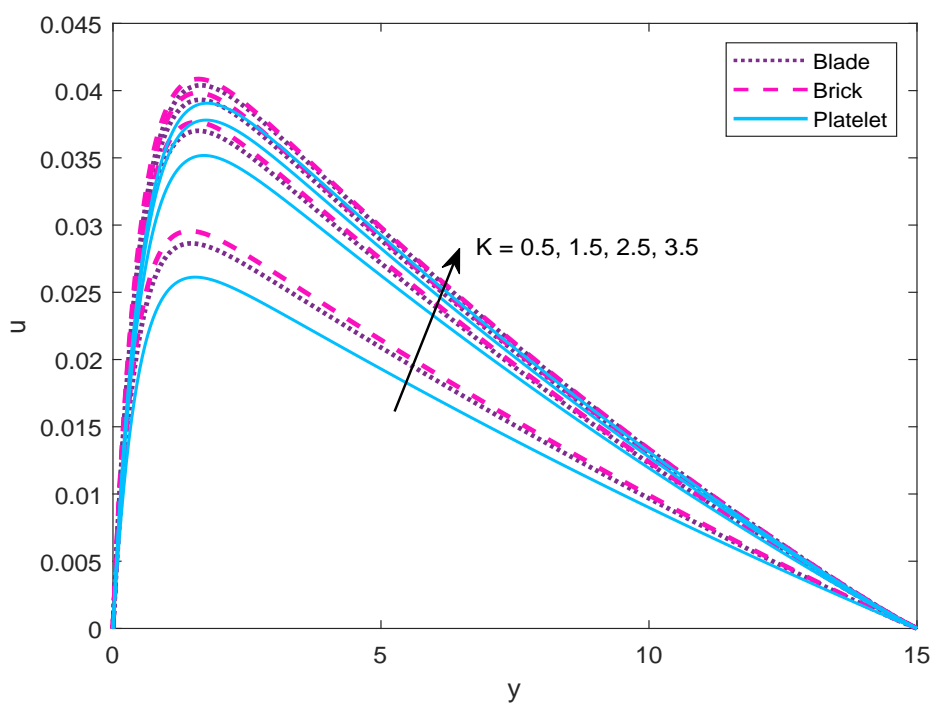

Figure 6. Influence of $K$ on velocity profile when $\varphi=0.01, \mathrm{Ha}=2, \mathrm{Gr}=0.3$, and $\mathrm{Rd}=3$. 


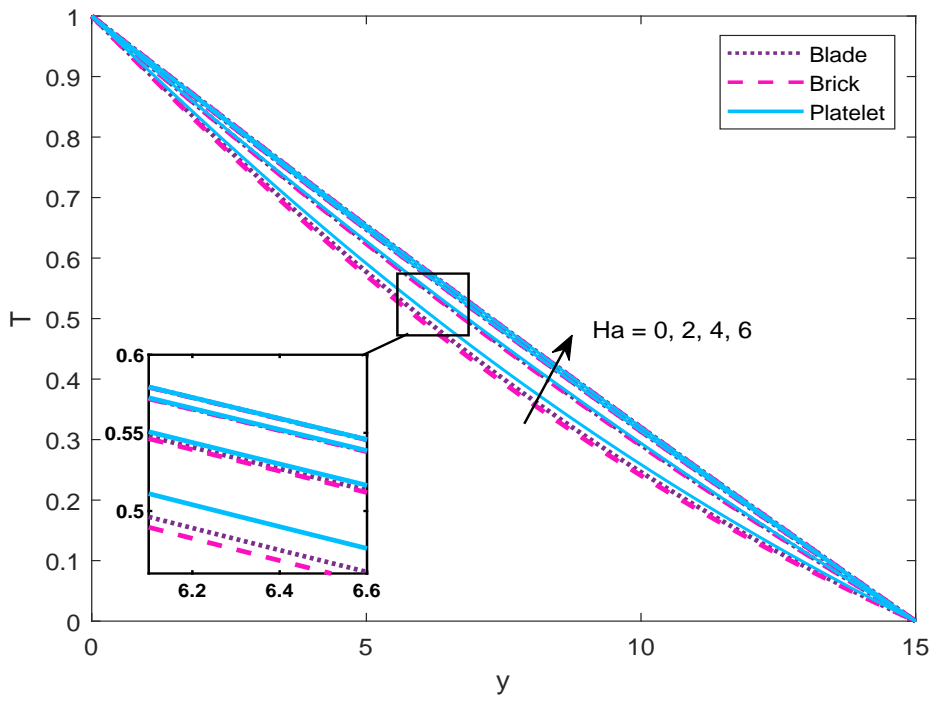

Figure 7. Influence of $H a$ on temperature distribution when $\varphi=0.01, K=0.5, G r=0.3$, and $R d=3$.

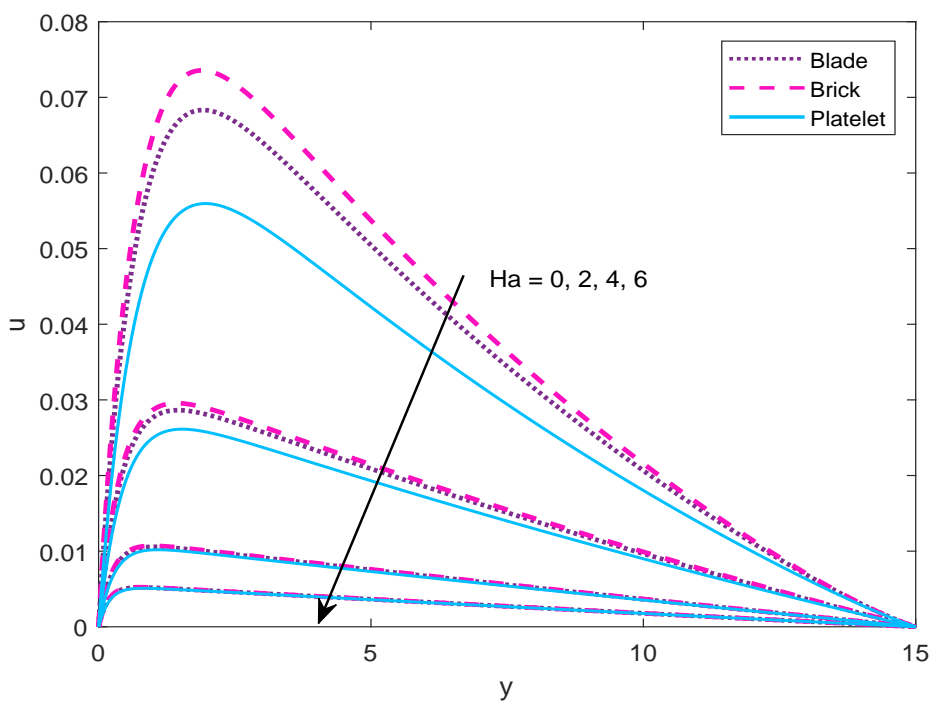

Figure 8. Influence of $H a$ on velocity profile when $\varphi=0.01, K=0.5, G r=0.3$, and $R d=3$.

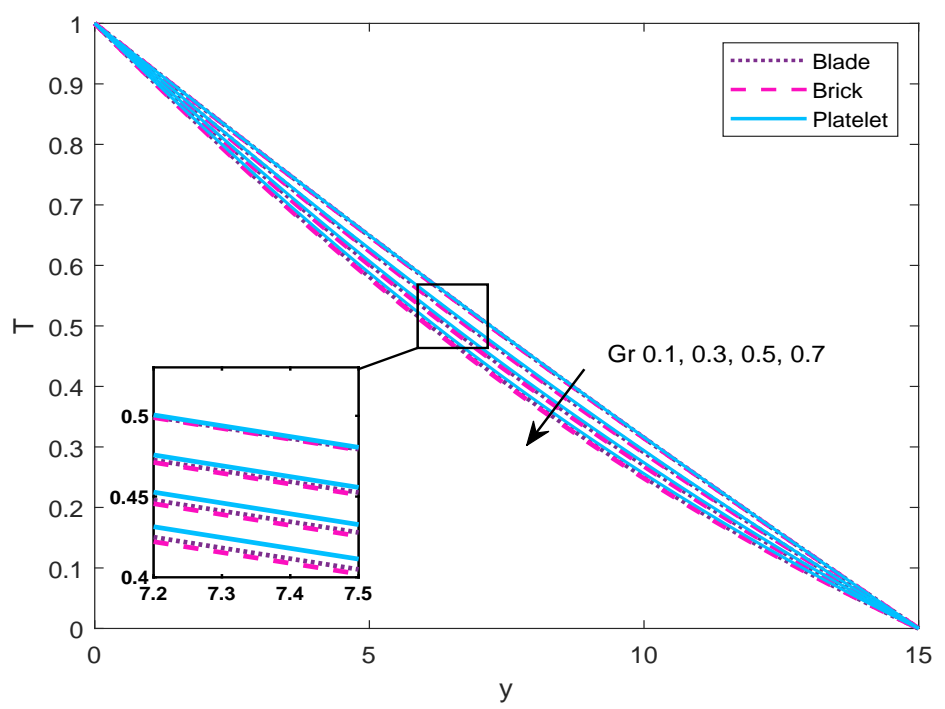

Figure 9. Influence of $\mathrm{Gr}$ on temperature distribution when $\varphi=0.01, K=0.5, H a=2$, and $R d=3$. 


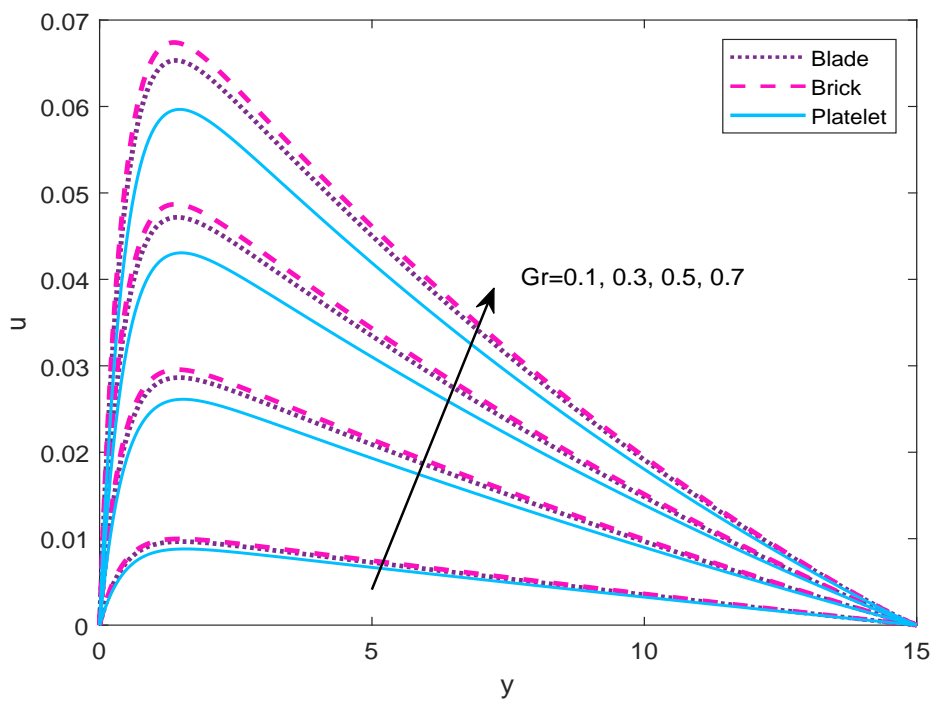

Figure 10. Influence of $G r$ on velocity profile when $\varphi=0.01, K=0.5, H a=2$, and $R d=3$.

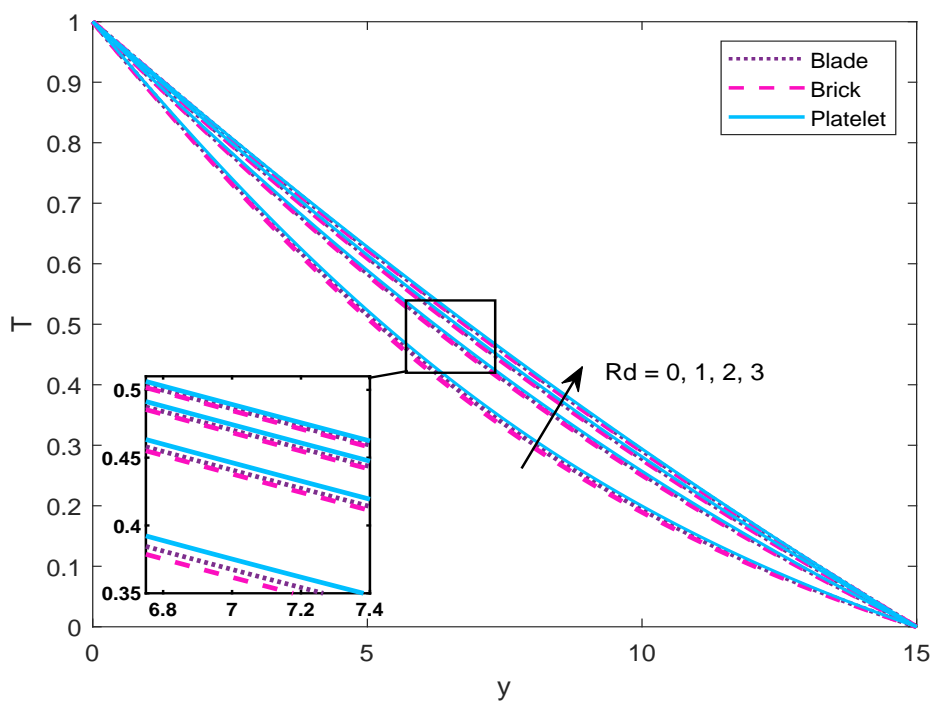

Figure 11. Influence of $R d$ on temperature distribution when $\varphi=0.01, K=0.5, H a=2$, and $G r=0.3$.

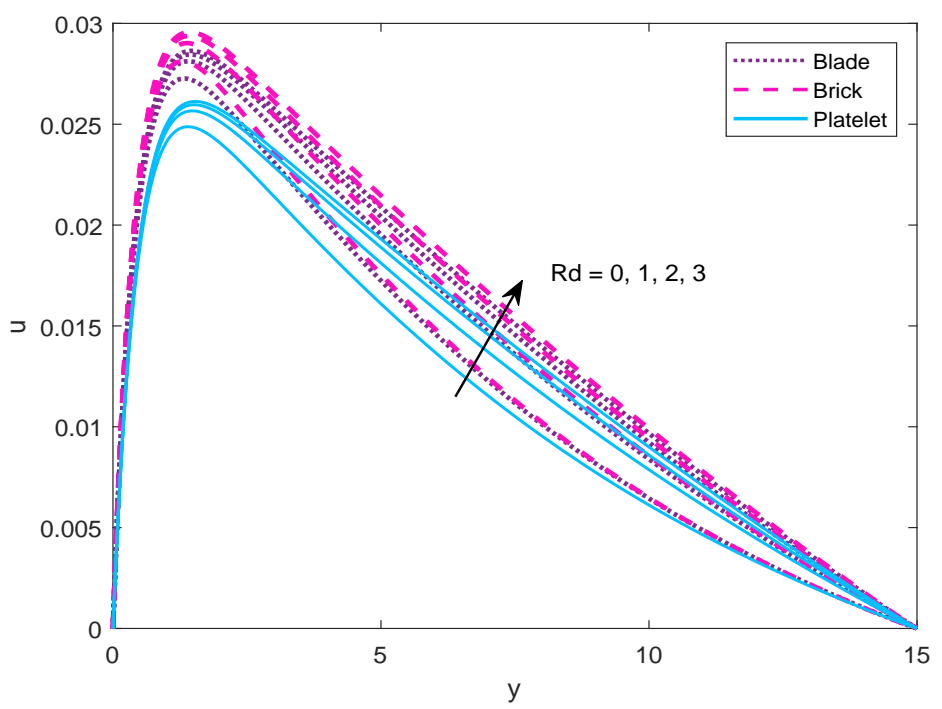

Figure 12. Influence of $R d$ on velocity profile when $\varphi=0.01, K=0.5, H a=2$, and $G r=0.3$. 
Figures 5 and 6 designate the effects of porosity parameter $K$ on temperature distribution and velocity profile, respectively. It is noticed that temperature distribution and velocity field decreases and increases respectively with an increase in porosity parameter. The brick-shaped particles possess lowest temperature and highest velocity rates followed by blade-shaped and platelet-shaped particles.

The behavior of Hartmann number $\mathrm{Ha}$ in the presence of three different shapes of CdTe nanoparticles on the temperature distribution and velocity profile of nanofluid are illustrated in Figures 7 and 8, respectively. The temperature distribution rises with an augment in the value of $\mathrm{Ha}$ whereas the velocity profile dropped off for higher values of $\mathrm{Ha}$.

In Figure 9, the variation of the thermal Grashof number $G r$ is examined on the temperature distribution of water based $C d T e$-nanofluid. It is noticed that the temperature distributions decreases by increasing the value of $\mathrm{Gr}$ and a maximum dropped down in the temperature graph is attained by brick-shaped particles. The velocity change due to $G r$ is plotted in Figure 10. For higher values of $G r$, a significant increase is observed in fluid flow. It is reasonable in the sense that maximum Grashof number is a source to upgrade the buoyancy force which buoyed up the nanofluid flow rates as a result the velocity field increases.

Figures 11 and 12 are plotted to examine the temperature distribution and velocity profile of $C d T e$ nanofluid against the variation in the radiation parameter $R d$. From the plots, it is evident that the temperature and velocity profiles increase when $R d$ is increased. This behavior is closed to physical expectations as the energy production causes elevation of the temperature and fluid flow.

Figures 13 and 14 display the variation in Nusselt number $N u_{x}$ and skin friction $\tau_{x}$ due to volume fraction $\varphi$ of $C d T e$ nanoparticles. It is noticed that both $N u_{x}$ and $\tau_{x}$ increase when $\varphi$ increases. It is important to bear in mind that blade-shaped particles have maximum sphericity compared to others. For the reason, the blade-shaped particles gained maximum values for $N u_{x}$. Platelet-shaped particles attained minimum Nusselt number for $(0<\varphi<0.035)$ than brick-shaped particles. On the other hand, maximum values for $\tau_{x}$ are obtained by platelet-shaped particles compared with blade and brick-shaped particles. The blade-shaped particles showed the highest rates of skin friction than brick-shaped particles when $(\varphi<0.035)$.

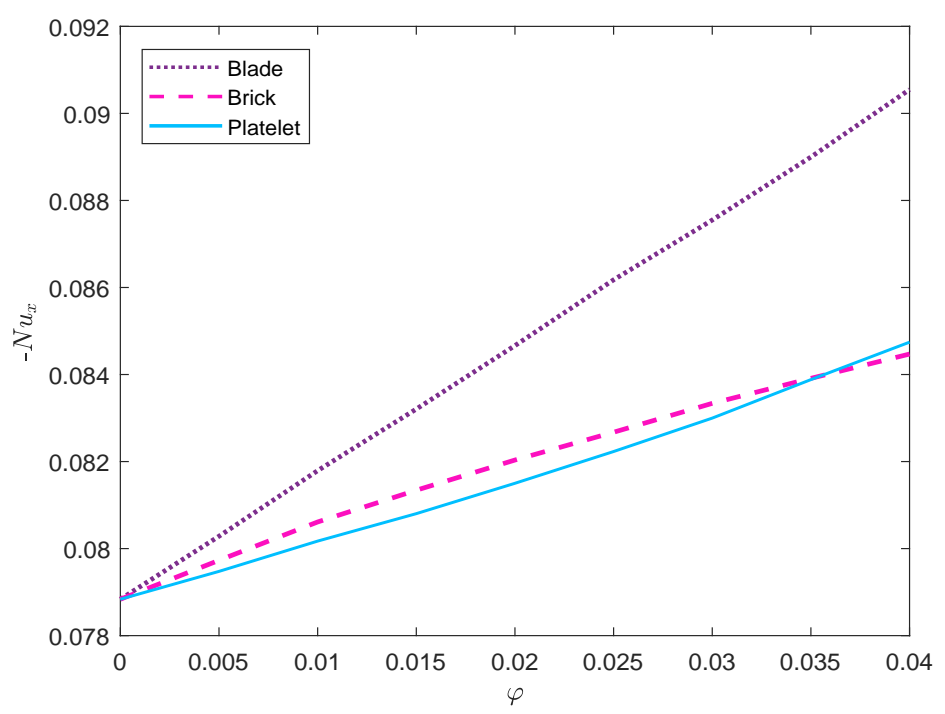

Figure 13. Influence of $\varphi$ on Nusselt number when $K=0.5, H a=2, G r=0.3$ and $R d=3$. 


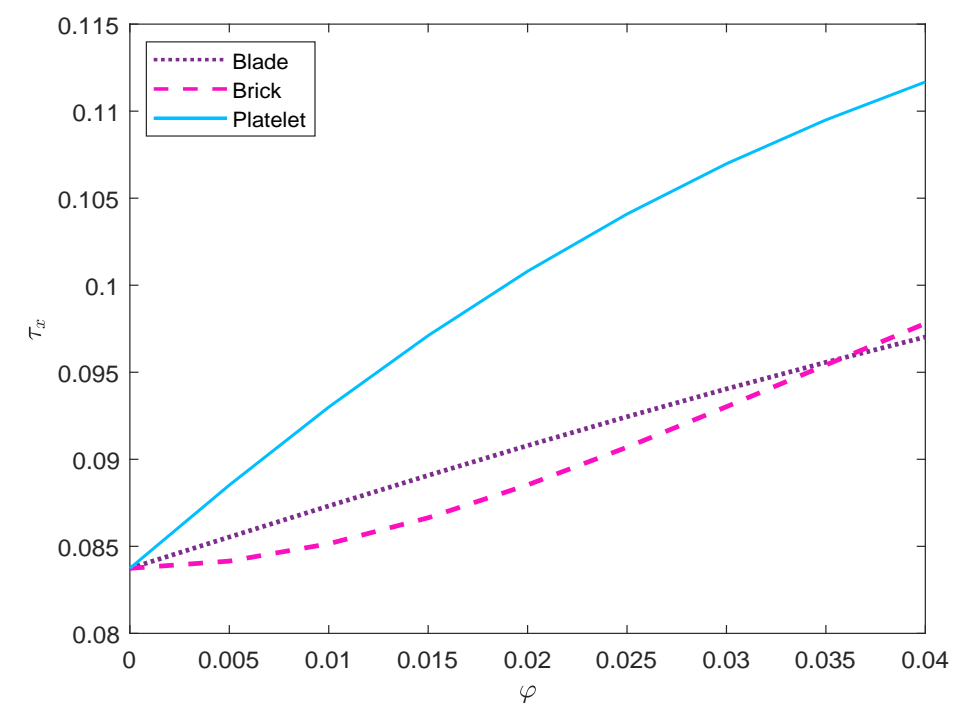

Figure 14. Influence of $\varphi$ on Skin friction when $K=0.5, H a=2, G r=0.3$ and $R d=3$.

In Figure 15, the thermal conductivity is plotted against CdTe particle volume fraction. It is evident from the plot that the thermal conductivity for blade-shaped particle increases maximum with respect to volume fraction than other particles. The result is sensible in a way that the blade type particle has the highest sphericity compared with platelet and brick particles. On the other hand, the values of shape constant $a_{0}$ and $b_{0}$ for platelet particles are higher than that of blade and brick. Owing to the fact, platelet type particles possessed maximum viscosity, as depicted in Figure 16.

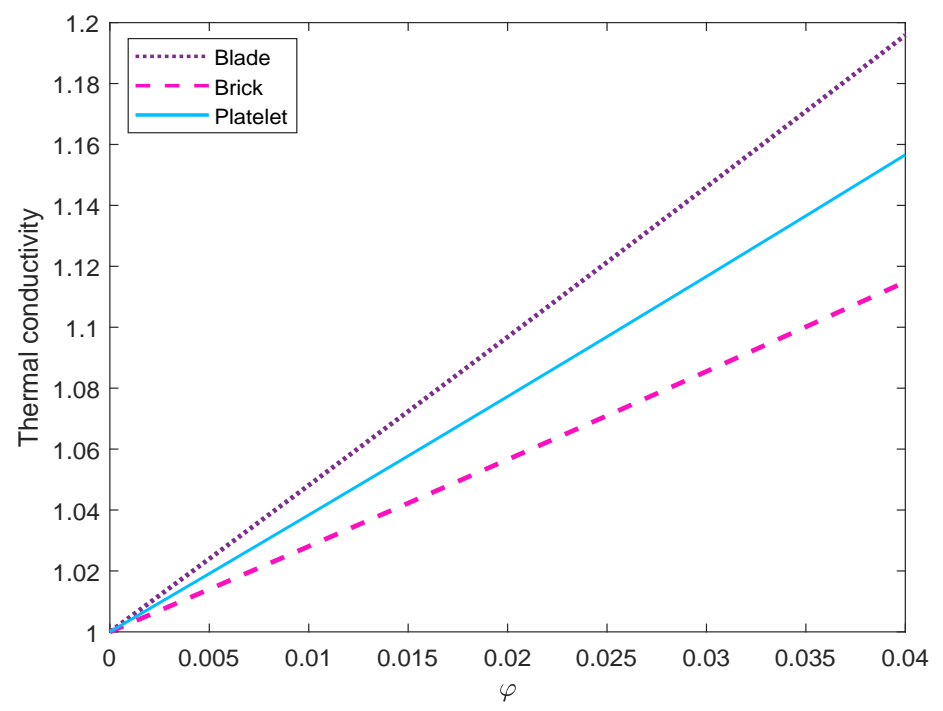

Figure 15. Dependence of thermal conductivity on volume fraction of $C d T e$ nanoparticles. 


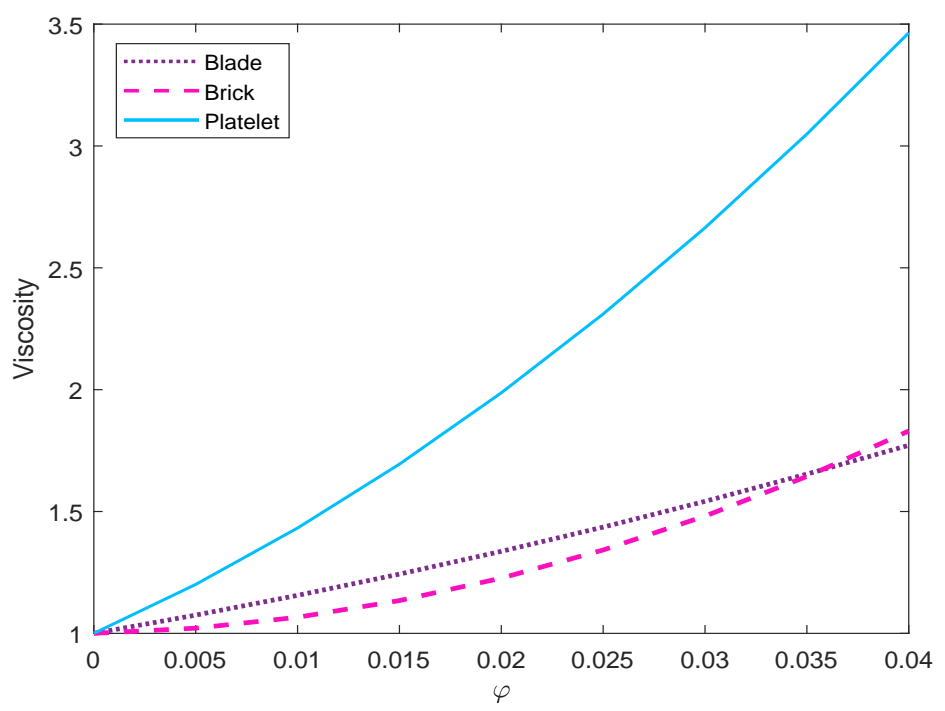

Figure 16. Dependence of viscosity on volume fraction of CdTe nanoparticles.

Tables 5-7 are tabulated to examine the effects of emerging parameters $(K, H a$, and $R d)$ on Nusselt number $N u_{x}$ and skin fiction $\tau_{x}$. The effects of porosity parameter $K$ on $N u_{x}$ and $\tau_{x}$ are tabulated in Table 5. It is found that the maximum Nusselt number is attained by the nanofluid in presence of blade-shaped particles compared with brick and platelet particles. However, the maximum skin friction for maximum value of $K$ is attained by platelet particles followed by blade and brick type particles.

Table 5. Nusselt number $\left(-N u_{x}\right)$ and skin friction $\left(\tau_{x}\right)$ for different values of $K$ at $x=1$ when $\varphi=0.01$, $H a=2, G r=0.3$, and $R d=3$.

\begin{tabular}{ccccccc}
\hline \multirow{2}{*}{$\boldsymbol{K}$} & \multicolumn{2}{c}{ Local Nusselt Number } & \multicolumn{3}{c}{ Local Skin Friction } \\
\cline { 2 - 7 } & Blade & Brick & Platelet & Blade & Brick & Platelet \\
\hline 0.5 & 0.3159 & 0.3158 & 0.3118 & 0.0874 & 0.0851 & 0.0930 \\
1.5 & 0.3271 & 0.3267 & 0.3242 & 0.1000 & 0.0967 & 0.1087 \\
2.5 & 0.3305 & 0.3299 & 0.3276 & 0.1032 & 0.0996 & 0.1130 \\
3.5 & 0.3317 & 0.3311 & 0.3295 & 0.1047 & 0.1010 & 0.1149 \\
\hline
\end{tabular}

Table 6. Nusselt number $\left(-N u_{x}\right)$ and skin friction $\left(\tau_{x}\right)$ for different values of $H a$ at $x=1$ when $\varphi=0.01, K=0.5, G r=0.3$, and $R d=3$.

\begin{tabular}{ccccccc}
\hline \multirow{2}{*}{$\boldsymbol{a} \boldsymbol{c}$} & \multicolumn{2}{c}{ Local Nusselt Number } & \multicolumn{2}{c}{ Local Skin Friction } \\
\cline { 2 - 7 } & Blade & Brick & Platelet & Blade & Brick & Platelet \\
\hline 0 & 0.03691 & 0.3743 & 0.3523 & 0.1388 & 0.1386 & 0.1394 \\
2 & 0.3159 & 0.3158 & 0.3118 & 0.0874 & 0.0851 & 0.0930 \\
4 & 0.2908 & 0.2896 & 0.2896 & 0.0522 & 0.0503 & 0.0571 \\
6 & 0.2834 & 0.2821 & 0.2826 & 0.0362 & 0.0348 & 0.0400 \\
\hline
\end{tabular}

Table 6 exhibits the impact of Hartmann number $H a$ on $N u_{x}$ and $\tau_{x}$. A reduction in the magnitude of Nusselt number and the skin friction of CdTe nanofluid are observed for higher values of $H a$. It is also noticed that the nanofluid with brick-shaped particles showed the highest Nusselt number in the absence of a magnetic field, otherwise the highest values for the Nusselt number were obtained by 
blade-shaped particles. Moreover, $C d T e$ nanofluid possesses larger values of Nusselt number with brick-shaped nanoparticles as compared to platelet-shaped particles when $H a<4$ and an opposite relation is observed when $\mathrm{Ha}>4$. The skin friction also shows decreasing effects by intensifying the values of the Hartmann number and a minimum decrease is obtained by nanofluid suspended with brick-shaped nanoparticles.

Table 7. Nusselt number $\left(-N u_{x}\right)$ and skin friction $\left(\tau_{x}\right)$ for different values of $R d$ at $x=1$ when $\varphi=0.01, K=0.5, H a=2$, and $\mathrm{Gr}=0.3$.

\begin{tabular}{ccccccc}
\hline \multirow{2}{*}{$\boldsymbol{d}$} & \multicolumn{2}{c}{ Local Nusselt Number } & \multicolumn{2}{c}{ Local Skin Friction } \\
\cline { 2 - 7 } & Blade & Brick & Platelet & Blade & Brick & Platelet \\
\hline 0 & 0.1144 & 0.1140 & 0.1108 & 0.0862 & 0.0840 & 0.0917 \\
1 & 0.1829 & 0.1828 & 0.1790 & 0.0869 & 0.0847 & 0.0925 \\
2 & 0.2496 & 0.2495 & 0.2456 & 0.0872 & 0.0850 & 0.0928 \\
3 & 0.3159 & 0.3158 & 0.3118 & 0.0874 & 0.0851 & 0.0930 \\
\hline
\end{tabular}

Table 7 reflects the impact of radiation parameter on $N u_{x}$ and $\tau_{x}$ and the result shows that both $N u_{x}$ and $\tau_{x}$ are increasing functions of the radiation parameter. It is also observed that the blade and brick shaped nanoparticles showed almost the same increasing rates for Nusselt number in the presence of thermal radiation. Furthermore, minimum Nusselt number $N u_{x}$ and maximum skin friction values $\tau_{x}$ are attained by platelet-shaped particles.

It is important to mention that different shapes of nano-sized particles only affect the thermal conductivity and viscosity of nanofluid. However, particle volume fraction not only enhances the thermal conductivity and viscosity of nanofluid, but also improves the values of other thermo-physical properties of fluid. Table 8 is drawn to display the numeric values of thermal conductivity $k_{n f}$ and viscosity $\mu_{n f}$ of $C d T e$ nanofluid using models from References [39,42]. From the table, it is clearly seen that $C d T e$ nanofluid with blade-shaped particles owned maximum thermal conductivity followed by platelet and brick type particles. Whereas the maximum viscosity of $C d T e$ nanofluid is obtained by platelet-shaped nanoparticles. In addition, the viscosity of blade-shaped particle is greater than that of brick-shaped particles for $(0<\varphi \leq 0.035)$. It is remarkable that the sequence of viscosity is followed by the velocity of different shapes of $C d T e$ nanoparticles, the platelet-shaped particles having the highest viscosity gives a lower velocity profile. But the temperature profiles showed a different sequence than the thermal conductivity of water based $C d T e$ nanofluid. A maximum thermal conductivity is attained in nanofluid containing blade-shaped $C d T e$ nanoparticles followed by platelet and brick type particles. Whereas the blade-shaped and platelet-shaped particles change the sequence in the temperature profile. It is worth mentioning that the behavior of temperature and velocity are not only affected by thermal conductivity and viscosity, but also by other thermo-physical properties. However, temperature distribution increases with respect to the volume fraction of all active-shapes of $C d T e$ nanoparticles. Also, the thermal conductivity and heat transfer rates of $C d T e$ nanofluid are greater than that of regular base fluid. Moreover, the thermal conductivity of $C d T e$-water nanofluid with blade, brick and platelet-shaped particles are $2.40 \%, 1.40 \%$ and $1.91 \%$ greater compared with simple water by adding a small amount $(\varphi=0.005)$ of $C d T e$ nanoparticles. The viscosity of platelet-shaped is $11.59 \%$ and $17.58 \%$ greater than viscosity of blade and brick-shaped nanoparticles, respectively. 
Table 8. Thermal conductivity and viscosity of $C d T e$-water nanofluid for different values of volume fraction $\varphi$.

\begin{tabular}{ccccccc}
\hline \multirow{2}{*}{$\boldsymbol{c}$} & \multicolumn{2}{c}{ Thermal Conductivity } & \multicolumn{3}{c}{ Viscosity } \\
\cline { 2 - 7 } & Blade & Brick & Platelet & Blade & Brick & Platelet \\
\hline 0 & 0.613 & 0.613 & 0.613 & $8.9000 \times 10^{-4}$ & $8.9000 \times 10^{-4}$ & $8.9000 \times 10^{-4}$ \\
0.005 & 0.6277 & 0.6216 & 0.6247 & $9.5771 \times 10^{-4}$ & $9.0894 \times 10^{-4}$ & $10.6873 \times 10^{-4}$ \\
0.01 & 0.6425 & 0.6302 & 0.6365 & $10.3091 \times 10^{-4}$ & $9.4886 \times 10^{-4}$ & $12.7471 \times 10^{-4}$ \\
0.015 & 0.6574 & 0.6389 & 0.6484 & $11.0960 \times 10^{-4}$ & $10.0916 \times 10^{-4}$ & $15.0796 \times 10^{-4}$ \\
0.02 & 0.6723 & 0.6471 & 0.6604 & $11.9377 \times 10^{-4}$ & $10.9164 \times 10^{-4}$ & $17.6847 \times 10^{-4}$ \\
0.025 & 0.6874 & 0.6565 & 0.6604 & $12.8344 \times 10^{-4}$ & $11.9449 \times 10^{-4}$ & $20.5623 \times 10^{-4}$ \\
0.03 & 0.7025 & 0.6654 & 0.6845 & $13.7858 \times 10^{-4}$ & $13.1832 \times 10^{-4}$ & $23.5623 \times 10^{-4}$ \\
0.035 & 0.7178 & 0.6744 & 0.6967 & $14.7922 \times 10^{-4}$ & $14.6313 \times 10^{-4}$ & $27.1355 \times 10^{-4}$ \\
0.04 & 0.7331 & 0.6834 & 0.7090 & $15.8534 \times 10^{-4}$ & $16.2891 \times 10^{-4}$ & $30.8310 \times 10^{-4}$ \\
\hline
\end{tabular}

\section{Conclusions}

In this study, a mathematical model of two-dimensional flow of water based nanofluid with suspension of non-spherical CdTe nanoparticles over an inverted cone is analyzed. The thermal conductivity $k_{n f}$ of non-spherical CdTe nanoparticles are obtained by the model in Reference [39]. Magnetic and thermal radiation effects inside a porous medium are also discussed. The effect of active parameters on temperature $T$, velocity $u$, Nusselt number $N u_{x}$ and skin friction $\tau_{x}$ are exhibited via graphs and tables. The analysis showed that

- the blade-shaped particles gained highest Nusselt number compared with platelet and brick type particles. It is reasonable in the sense that blade-shaped particles have higher sphericity than platelet and brick type particles. Therefore, the blade-shaped particles possessed the highest rates for the Nusselt number.

- the temperature distribution increases with an augment in particle volume fraction, radiation parameter and Hartmann number, whereas a reverse relation exists for porosity and Grashof number.

- the highest viscosity is owned by platelet-shaped particles.

- the viscosity of blade-shaped particles is higher than that of brick-shaped particles when $(\varphi<0.04)$.

- the thermal conductivity of blade-shaped particles is $1.93 \%$ and $0.94 \%$ greater than brick and platelet-shaped nanoparticles when $\varphi=0.01$.

Author Contributions: Formulation done by H.H. and S.S. Problem solved by H.H. and I.K. Results computed by H.H.; S.S. and W.A.K. Results discussed by I.K. and W.A.K. All authors contributed equally in writing manuscript. All authors have read and agreed to the published version of the manuscript.

Acknowledgments: The research is conducted with financial support by SBK Women's University, Pakistan (SBKWU FDP Split Scholarship Phase-3) for which the authors are highly indebted.

Funding: This research received no external funding.

Conflicts of Interest: The authors declare no conflict of interest.

\section{Nomenclature}

$B_{0} \quad$ magnetic field strength

$C_{p}$ heat capacitance

$\mathrm{Gr}$ Grashof number 
$\mathrm{Ha}$ Hartmann number

$K$ dimensionless permeability parameter

$k$ thermal conductivity

$k_{0} \quad$ permeability of porous medium

$k_{b}$ absorption coefficient

$L$ reference length

$N u_{x} \quad$ Nusselt number

$\mathrm{Pe}$ Peclet number

$r$ radius of cone

$R d$ radiation parameter

Re Reynold number

\section{Greek letters}

$\beta$ thermal expansion

$\mu$ dynamic viscosity

$\nabla$ gradient operator

$v$ kinematic viscosity

$\phi$ half angle of cone

$\rho$ density

$\sigma$ electrical conductivity

$\sigma_{b} \quad$ Stefan-Boltzman coefficient

$\tau_{x}$ skin friction coefficient

$\varphi$ nanoparticle volume fraction

\section{Subscripts}

$\mathrm{f}$ base fluid

nf nanofluid

s nanoparticles

\section{References}

1. Wald, F. Applications of CdTe. A review. Revue de Physique Appliquée 1977, 12, 277-290.

2. Ferekides, C.; Balasubramanian, U.; Mamazza, R.; Viswanathan, V.; Zhao, H.; Morel, D. CdTe thin film solar cells: device and technology issues. Sol. Energy 2004, 77, 823-830.

3. Volchkov, I.; Kanevskii, V.M.; Pavlyuk, M. Effect of weak magnetic fields on the electric properties of CdTe crystals. JETP Lett. 2018, 107, 269-272.

4. Himanshu, S.L.; Patel, S.; Chander, S.; Singh, P.; Thakur, A.; Dhaka, M.S. Bi-incorporated CdTe thin films for solar cells: Air annealing evolution to structural, optical, electrical and surface topographical properties. Mater. Lett. 2019, 249, 29-32.

5. Patel, S.; Chander, S.; Purohit, A.; Kannan, M.; Dhaka, M. Influence of $\mathrm{NH}_{4} \mathrm{Cl}$ treatment on physical properties of CdTe thin films for absorber layer applications. J. Phys. Chem. Solids 2018, 123, 216-222.

6. Chander, S.; Dhaka, M. Enhancement in microstructural and optoelectrical properties of thermally evaporated CdTe films for solar cells. Results Phys. 2018, 8, 1131-1135.

7. Awni, R.A.; Li, D.B.; Song, Z.; Bista, S.S.; Razooqi, M.A.; Grice, C.R.; Chen, L.; Liyanage, G.K.; Li, C.; Phillips, A.B.; et al. Influences of buffer material and fabrication atmosphere on the electrical properties of CdTe solar cells. Prog. Photovolt. Res. Appl. 2019, doi:10.1002/pip.3192.

8. Hanif, H.; Khan, I.; Shafie, S. MHD natural convection in cadmium telluride nanofluid over a vertical cone embedded in a porous medium. Physica Scripta 2019, 94, 125208.

9. Nazari, M.A.; Ghasempour, R.; Ahmadi, M.H.; Heydarian, G.; Shafii, M.B. Experimental investigation of graphene oxide nanofluid on heat transfer enhancement of pulsating heat pipe. Int. Commun. Heat Mass Transf. 2018, 91, 90-94.

10. Bhanvase, B.; Sayankar, S.; Kapre, A.; Fule, P.; Sonawane, S. Experimental investigation on intensified convective heat transfer coefficient of water based PANI nanofluid in vertical helical coiled heat exchanger. Appl. Therm. Eng. 2018, 128, 134-140. 
11. Monroe, J.G.; Kumari, S.; Fairley, J.D.; Walters, K.B.; Berg, M.J.; Thompson, S.M. On the energy harvesting and heat transfer ability of a ferro-nanofluid oscillating heat pipe. Int. J. Heat Mass Transf. 2019, 132, 162-171.

12. Jaferian, V.; Toghraie, D.; Pourfattah, F.; Akbari, O.A.; Talebizadehsardari, P. Numerical investigation of the effect of water $/ \mathrm{Al}_{2} \mathrm{O}_{3}$ nanofluid on heat transfer in trapezoidal, sinusoidal and stepped microchannels. Int. J. Numer. Methods Heat Fluid Flow 2019.

13. Radkar, R.; Bhanvase, B.; Barai, D.; Sonawane, S. Intensified convective heat transfer using $\mathrm{ZnO}$ nanofluids in heat exchanger with helical coiled geometry at constant wall temperature. Mater. Sci. Energy Technol. 2019, 2, 161-170.

14. Ahmed, N.; Khan, U.; Zaidi, S.Z.A.; Faisal, I.; Mohyud-Din, S.T. Heat transfer intensification in hydromagnetic and radiative 3D unsteady flow regimes: A comparative theoretical investigation for aluminum and $\gamma$-aluminum oxides nanoparticles. J. Cent. South Univ. 2019, 26, 1233-1249.

15. Khan, I. Shape effects of $\mathrm{MoS}_{2}$ nanoparticles on MHD slip flow of molybdenum disulphide nanofluid in a porous medium. J. Mol. Liquids 2017, 233, 442-451.

16. Hassan, M.; Zeeshan, A.; Majeed, A.; Ellahi, R. Particle shape effects on ferrofuids flow and heat transfer under influence of low oscillating magnetic field. J. Magn. Magn. Mater. 2017, 443, 36-44.

17. Sheikholeslami, M.; Bhatti, M. Forced convection of nanofluid in presence of constant magnetic field considering shape effects of nanoparticles. Int. J. Heat Mass Transf. 2017, 111, 1039-1049.

18. Sheikholeslami, M.; Shehzad, S.; Li, Z.; Shafee, A. Numerical modeling for alumina nanofluid magnetohydrodynamic convective heat transfer in a permeable medium using Darcy law. Int. J. Heat Mass Transf. 2018, 127, 614-622.

19. Hassan, M.; Fetecau, C.; Majeed, A.; Zeeshan, A. Effects of iron nanoparticles' shape on convective flow of ferrofluid under highly oscillating magnetic field over stretchable rotating disk. J. Magn. Magn. Mater. 2018, 465, 531-539.

20. Hamid, M.; Usman, M.; Zubair, T.; Haq, R.U.; Wang, W. Shape effects of $M o S_{2}$ nanoparticles on rotating flow of nanofluid along a stretching surface with variable thermal conductivity: A Galerkin approach. Int. J. Heat Mass Transf. 2018, 124, 706-714.

21. Sheikholeslami, M.; Shamlooei, M.; Moradi, R. Numerical simulation for heat transfer intensification of nanofluid in a porous curved enclosure considering shape effect of $\mathrm{Fe}_{3} \mathrm{O}_{4}$ nanoparticles. Chem. Eng. Process. Process Intensif. 2018, 124, 71-82.

22. Akbar, N.S.; Huda, A.B.; Habib, M.B.; Tripathi, D. Nanoparticles shape effects on peristaltic transport of nanofluids in presence of magnetohydrodynamics. Microsyst. Technol. 2019, 25, 283-294.

23. Shi, X.; Jaryani, P.; Amiri, A.; Rahimi, A.; Malekshah, E.H. Heat transfer and nanofluid flow of free convection in a quarter cylinder channel considering nanoparticle shape effect. Powder Technol. 2019, 346, 160-170.

24. Kumar, K.G.; Chamkha, A.J. Darcy-Forchheimer flow and heat transfer of water-based Cu nanoparticles in convergent/divergent channel subjected to particle shape effect. Eur. Phys. J. Plus 2019, 134, 107.

25. Al-Rashed, A.A.; Ranjbarzadeh, R.; Aghakhani, S.; Soltanimehr, M.; Afrand, M.; Nguyen, T.K. Entropy generation of boehmite alumina nanofluid flow through a minichannel heat exchanger considering nanoparticle shape effect. Physica A Stat. Mech. Appl. 2019, 521, 724-736.

26. Shahsavar, A.; Rahimi, Z.; Salehipour, H. Nanoparticle shape effects on thermal-hydraulic performance of boehmite alumina nanofluid in a horizontal double-pipe minichannel heat exchanger. Heat Mass Transf. 2019, 55, 1741-1751.

27. Morgan, E.; Wupperfeld, D.; Morales, D.; Reich, N. Shape matters: Gold nanoparticle shape impacts the biological activity of siRNA delivery. Bioconj. Chem. 2019, 30, 853-860.

28. García-Álvarez, R.; Hadjidemetriou, M.; Sánchez-Iglesias, A.; Liz-Marzán, L.M.; Kostarelos, K. In vivo formation of protein corona on gold nanoparticles. The effect of their size and shape. Nanoscale 2018, $10,1256-1264$.

29. Liu, F.; Cai, Y.; Wang, L.; Zhao, J. Effects of nanoparticle shapes on laminar forced convective heat transfer in curved ducts using two-phase model. Int. J. Heat Mass Transf. 2018, 116, 292-305.

30. Kilymis, D.; Gérard, C.; Amodeo, J.; Waghmare, U.; Pizzagalli, L. Uniaxial compression of silicon nanoparticles: an atomistic study on the shape and size effects. Acta Materialia 2018, 158, 155-166.

31. Ma, Y.; Mohebbi, R.; Rashidi, M.; Yang, Z.; Sheremet, M.A. Numerical study of MHD nanofluid natural convection in a baffled U-shaped enclosure. Int. J. Heat Mass Transf. 2019, 130, 123-134. 
32. Capper, P. Properties of Narrow Gap Cadmium-Based Compounds; Number 10; INSPEC, the Institute of Electrical Engineering: London, UK, 1994.

33. Koç, H.; Eser, E. Estimation of the heat capacity of CdTe semiconductor. Modern Physics Lett. B 2016, 30, 1650026.

34. Strauss, A. The physical properties of cadmium telluride. Revue de Physique Appliquée 1977, 12, 167-184.

35. Chattopadhyay, K.; Feth, S.; Chen, H.; Burger, A.; Su, C.H. Characterization of semi-insulating CdTe crystals grown by horizontal seeded physical vapor transport. J. Cryst. Growth 1998, 191, 377-385.

36. Ellahi, R.; Hassan, M.; Zeeshan, A. Shape effects of nanosize particles in $\mathrm{Cu}-\mathrm{H}_{2} \mathrm{O}$ nanofluid on entropy generation. Int. J. Heat Mass Transf. 2015, 81, 449-456.

37. Sheikholeslami, M.; Ganji, D.; Moradi, R. Heat transfer of $\mathrm{Fe}_{3} \mathrm{O}_{4}$-water nanofluid in a permeable medium with thermal radiation in existence of constant heat flux. Chem. Eng. Sci. 2017, 174, 326-336.

38. Marinca, B.; Marinca, V. Some exact solutions for MHD flow and heat transfer to modified second grade fluid with variable thermal conductivity in the presence of thermal radiation and heat generation/absorption. Comput. Math. Appl. 2018, 76, 1515-1524.

39. Hamilton, R.L.; Crosser, O. Thermal conductivity of heterogeneous two-component systems. Ind. Eng. Chem. Fundam. 1962, 1, 187-191.

40. Yih, K. Effect of radiation on natural convection about a truncated cone. Int. J. Heat Mass Transf. 1999, 42, 4299-4305.

41. Chamkha, A.J.; Rashad, A.; Al-Mudhaf, H.F. Heat and mass transfer from truncated cones with variable wall temperature and concentration in the presence of chemical reaction effects. Int. J. Numer. Methods Heat Fluid Flow 2012, 22, 357-376.

42. Timofeeva, E.V.; Routbort, J.L.; Singh, D. Particle shape effects on thermophysical properties of alumina nanofluids. J. Appl. Phys. 2009, 106, 014304.

(C) 2019 by the authors. Licensee MDPI, Basel, Switzerland. This article is an open access article distributed under the terms and conditions of the Creative Commons Attribution (CC BY) license (http:/ / creativecommons.org/licenses/by/4.0/). 